Mike Hughes: None declared, Francesco Del Galdo: None declared, Rosaria Irace: None declared, Oliver Distler Grant/research support from: OD (last three years) has/had consultancy relationship and/or has received research funding in the area of potential treatments for systemic sclerosis and its complications from (last three years): Abbvie, Acceleron Pharma, Amgen, AnaMar, Arxx Therapeutics, Baecon Discovery, Blade Therapeutics, Bayer, Boehringer Ingelheim, ChemomAb, Corbus Pharmaceuticals, CSL Behring, Galapagos NV, Glenmark Pharmaceuticals, GSK, Horizon (Curzion) Pharmaceuticals, Inventiva, iQvia, Italfarmaco, iQone, Kymera Therapeutics, Lilly, Medac, Medscape, Mitsubishi Tanabe Pharma, MSD, Novartis, Pfizer, Roche, Sanofi, Serodapharm, Topadur, Target Bioscience and UCB. Patent issued "mir-29 for the treatment of systemic sclerosis" (US8247389, EP2331143)., Valeria Riccieri: None declared, Yannick Allanore Speakers bureau: YA received personal fees from Boehringer, Sanofi, Menarini and Medsenic and grants from Alpine with regards to the management of systemic sclerosis, Grant/research support from: YA received personal fees from Boehringer, Sanofi, Menarini and Medsenic and grants from Alpine with regards to the management of systemic sclerosis, Ana Maria Gheorghiu: None declared, Elise Siegert: None declared, Jeska de Vries-Bouwstra: None declared, Eric Hachulla: None declared, Mohammed Tikly: None declared, Nemanja Damjanov: None declared, Francois Spertini: None declared, Luc Mouthon: None declared, Anna-Maria Hoffmann-Vold Speakers bureau: AMHV: received consulting fees from Actelion, ARXX, Bayer, Boehringer Ingelheim, Lilly, Medscape, Merck Sharp \& Dohme and Roche; and grants from Boehringer Ingelheim., Consultant of: AMHV: received consulting fees from Actelion, ARXX, Bayer, Boehringer Ingelheim, Lilly, Medscape, Merck Sharp \& Dohme and Roche; and grants from Boehringer Ingelheim., Grant/research support from: AMHV: received consulting fees from Actelion, ARXX, Bayer, Boehringer Ingelheim, Lilly, Medscape, Merck Sharp \& Dohme and Roche; and grants from Boehringer Ingelheim., Armando Gabrielli: None declared, Serena Guiducci: None declared, Marco Matucci-Cerinic Speakers bureau: has received consulting fees or honorarium from Actelion, Janssen, Inventiva, Bayer, Biogen, Boehringer, CSL Behring, Corbus, Galapagos, Mitsubishi, Samsung, Regeneron, Acceleron, MSD, Chemomab, Lilly, Pfizer, Roche, Grant/research support from: has received consulting fees or honorarium from Actelion, Janssen, Inventiva, Bayer, Biogen, Boehringer, CSL Behring, Corbus, Galapagos, Mitsubishi, Samsung, Regeneron, Acceleron, MSD, Chemomab, Lilly, Pfizer, Roche, Daniel Furst: None declared, Silvia Bellando Randone: None declared

DOI: 10.1136/annrheumdis-2021-eular.3027

\section{POS0318 CLINICAL PHENOTYPE IN SCLERODERMA PATIENTS WITH ANTI-TOPOISOMERASE I POSITIVITY AND LIMITED CUTANEOUS FORM: DATA FROM THE EUSTAR DATABASE}

E. Zanatta ${ }^{1}$, D. Huscher ${ }^{2}$, P. Airò ${ }^{3}$, A. Balbir-Gurman ${ }^{4}$, E. Siegert ${ }^{5}$, A. Ortolan ${ }^{1}$ M. Matucci-Cerinic ${ }^{6}$, F. Cozzi ${ }^{7}$, G. Riemekasten ${ }^{8}$, A. M. Hoffmann-Vold ${ }^{9}$, O. Distler ${ }^{10}$, A. Gabrielli $i^{11}$, S. Heitmann ${ }^{12}$, N. Hunzelmann ${ }^{13}$, C. Montecucco ${ }^{14}$ J. Morovic-Vergles ${ }^{15}$, C. Ribi ${ }^{16}$, A. Doria ${ }^{1}$, Y. Allanore ${ }^{17}$ on behalf of on behalf of EUSTAR collaborators. ${ }^{1}$ University Hospital of Padova, Department of Medicine, Rheumatology Unit, Padova, Italy; ${ }^{2}$ Charité-Universitaetsmedizin, Institute of Biometry and Clinical Epidemiology and Berlin Institute of Health, Berlin, Germany; ${ }^{3}$ Spedali Civili, Rheumatology and Clinical Immunology, Brescia, Italy; ${ }^{4}$ Rappaport Faculty of Medicine, B. Shine Rheumatology Institute Rambam Health Care Campus, Technion, Haifa, Israel; ${ }^{5}$ Charité-Universitatsmedizin Berlin, Department of Rheumatology and Clinical Immunology, Berlin, Germany; ${ }^{6}$ University of Florence, Department of Experimental and Clinical Medicine, Division of Rheumatology, Florence, Italy; ${ }^{7}$ Ospedale Classificato Villa Salus, Internal Medicine Unit, Venice, Italy; ${ }^{8}$ Universitatsklinikum Schleswig HolsteinCampus Lubeck, Department of Rheumatology, Lubeck, Germany; ${ }^{9}$ Oslo University Hospital, Department of Rheumatology, Oslo, Norway; ${ }^{10}$ University Hospital Zurich, University of Zurich, Department of Rheumatology, Zurich, Switzerland; ${ }^{11}$ Università Politecnica delle marche, Dipartimento di Scienze Cliniche e molecolari, Ancona, Italy; ${ }^{12}$ Marienhospital Stuttgart Böheimstrasse, Department of Rheumatology, Stuttgart, Germany; ${ }^{13}$ University of Cologne, Department of Dermatology, Koln, Nordrhein-Westfalen, Germany; ${ }^{14}$ IRCCS Policlinico San Matteo Foundation, Department of Rheumatology, Pavia, Italy; ${ }^{15}$ Dubrava University Hospital, Department of Internal Medicine, Division of Clinical Immunology, Allergology and Rheumatology, Zagreb, Croatia;

${ }^{16}$ Lausanne University Hospital and University of Lausanne, Department of Rheumatology, Clinical Immunology and Allergy, Lausanne, Switzerland; ${ }^{17}$ Cochin Hospital, University of Paris Descartes, Department of Rheumatology, Paris, France

Background: There is renewed interest in the role of autoantibodies to predict outcomes in systemic sclerosis (SSc). Among the newly identified subsets, patients with limited cutaneous form (IcSSc) but anti-topoisomerase I antibodies (Scl70) positivity draw particular attention, and namely, assessing the risk of developing interstitial lung disease (ILD) -the main cause of death in SSc-to improve the management of Scl70-IcSSc patients.
Objectives: We aimed to characterize patients with Scl70-IcSSc in the large multicenter European Scleroderma Trial and Research (EUSTAR) cohort.

Methods: The EUSTAR database was locked in July 2019. We included all patients fulfilling 1980 ACR and/or 2013 ACR/EULAR criteria for SSc, with disease duration at database entry $\leq 3$ yrs and known and stable skin form during the first 3 yrs. Patients with IcSSc were compared: Scl70-IcSSc (target group) vs. ACA-IcSSc and ANA-IcSSc (Step 1); and Scl70-IcSSc vs. Scl70-dcSSc (Step 2). In the ANA subgroup we included ANA+ patients with negative SSc-specific antibodies (ScI70, ACA, RNA polymerase III). In each step, we performed 5 generalized mixed models (GMM) for the risk of the new onset of ILD (defined by imaging), primary myocardial involvement (PMI), pulmonary hypertension $(\mathrm{PH})$, "any severe" (ILD+PMI+PH+scleroderma renal crisis) and all-cause-mortality. An additional GMM assessed the risk of forced vital capacity (FVC) decline $\geq 10 \%$ vs. FVC value at ILD onset. Each GMM was adjusted for age, sex and confounders Results: Overall, 1285 SSc patients were included: 1068 (83\%) females, 860 $(67 \%)$ IcSSc and 425 (33\%) dcSSc. Among patients with IcSSc, $537(62 \%)$ had ACA+, 194 (23\%) Scl70+ and 129 (15\%) ANA+; 425 patients had dcSSc and Scl70+. Median follow-up was similar in all 4 groups: 7.2 to $8.1 \mathrm{yrs}$.

Step 1: At baseline, Scl70-IcSSc patients had significantly shorter time from Raynaud's phenomenon (RP) to SSc onset, higher mRSS (5.8 \pm 4.8 vs. $4.3 \pm 4$ $\mathrm{p}=0.001$ ), and higher rate of articular and muscular involvement vs. ACA-lcSSc patients (Figure 1). No differences were found between Scl70-IcSSc and ANAIcSSc comparing the aforementioned variables. ILD was more frequent in Scl70-IcSSc (46\%) than in ACA-IcSSc (10\%) and ANA-IcSSc (25\%), as well as restrictive lung disease. GMM showed that Scl70-IcSSc carries a higher risk of ILD than both ACA-IcSSc (HR 4.55, 95\% Cl 3.23-6.67) and ANA-IcSSc (HR 2.17, $95 \% \mathrm{Cl} 1.39-3.45$ ), with a rate of FVC decline $\geq 10 \%$ over time similar to the other limited forms. In Scl70-IcSSc patients the risk of "any severe" organ involvement was similar to ANA-IcSSc and higher than ACA-IcSSc (HR 1.89, 95\% Cl 1.402.50). In particular, Scl70-IcSSc shows a risk of PMI similar to ANA-IcSSc and lower than ACA-lcSSc; no differences regarding PH risk. The mortality risk in patients with Scl70-IcSSc was similar to the other limited forms'

Step 2: At baseline, time from RP to SSc onset was longer in patients with Scl70IcSSc, with less frequent joint synovitis and tendon friction rubs vs. patients with Scl70-dcSSc. Conversely, the frequency of muscular, cardiac and pulmonary involvement was similar. The risk of ILD in Scl70-IcSSc patients was similar to Scl70-dcSSc, with a lower risk of FVC decline $\geq 10 \%$ over time. The risk of "any severe" involvement ( $\mathrm{HR} 0.66,95 \% \mathrm{Cl} 0.49-0.83$ ), $\mathrm{PMI}$ and $\mathrm{PH}$ was lower and the mortality risk tended to be lower ( $\mathrm{HR} 0.57,95 \% \mathrm{Cl} 0.33-1.01, \mathrm{p}=0.053$ ) vs. Scl70-dcSSc.

Conclusion: In our large multicenter EUSTAR cohort one quarter of IcSSc patients were Scl70+. We show a ranking for major organ involvement within IcSSc: Scl70 the most severe, ANA+ intermediate and ACA the milder form. Scl70-dcSSc patients present the most severe phenotype, and Scl70 positivity, more than the cutaneous subset, is strongly predictive of ILD, whereas other variables may influence progression. These results may provide new insight to improve the management of Scl70-IcSSc patients.

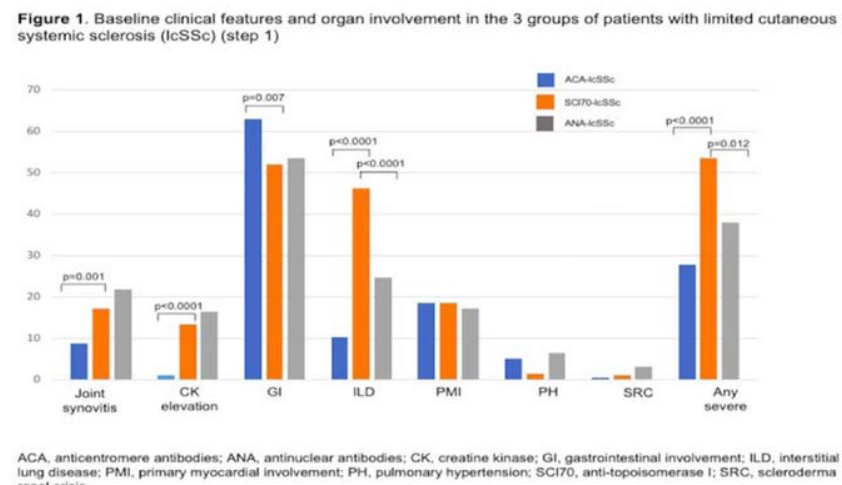

Disclosure of Interests: Elisabetta Zanatta: None declared, Dörte Huscher None declared, Paolo Airò: None declared, Alexandra Balbir-Gurman: None declared, Elise Siegert: None declared, Augusta Ortolan: None declared, Marco Matucci-Cerinic: None declared, Franco Cozzi: None declared, Gabriela Riemekasten: None declared, Anna-Maria Hoffmann-Vold: None declared, Oliver Distler Speakers bureau: has/had consultancy relationship and/or has received research funding in the area of potential treatments for systemic sclerosis and its complications from (last three years): Abbvie, Acceleron Pharma, Amgen, AnaMar, Arxx Therapeutics, Baecon Discovery, Blade Therapeutics, Bayer Boehringer Ingelheim, ChemomAb, Corbus Pharmaceuticals, CSL Behring, Galapagos NV, Glenmark Pharmaceuticals, GSK, Horizon (Curzion) Pharmaceuticals, Inventiva, iQvia, Italfarmaco, iQone, Kymera Therapeutics, Lilly, Medac 
Medscape, Mitsubishi Tanabe Pharma, MSD, Novartis, Pfizer, Roche, Sanofi, Serodapharm, Topadur, Target Bioscience and UCB. Patent issued "mir-29 for the treatment of systemic sclerosis" (US8247389, EP2331143)., Consultant of: has/had consultancy relationship and/or has received research funding in the area of potential treatments for systemic sclerosis and its complications from (last three years): Abbvie, Acceleron Pharma, Amgen, AnaMar, Arxx Therapeutics, Baecon Discovery, Blade Therapeutics, Bayer, Boehringer Ingelheim, ChemomAb, Corbus Pharmaceuticals, CSL Behring, Galapagos NV, Glenmark Pharmaceuticals, GSK, Horizon (Curzion) Pharmaceuticals, Inventiva, iQvia, Italfarmaco, iQone, Kymera Therapeutics, Lilly, Medac, Medscape, Mitsubishi Tanabe Pharma, MSD, Novartis, Pfizer, Roche, Sanofi, Serodapharm, Topadur, Target Bioscience and UCB. Patent issued "mir-29 for the treatment of systemic sclerosis" (US8247389, EP2331143)., Grant/research support from: Kymera Therapeutics, Mitsubishi Tanabe, Armando Gabrielli: None declared, Stefan Heitmann: None declared, Nicolas Hunzelmann: None declared, Carlomaurizio Montecucco: None declared, Jadranka Morovic-Vergles: None declared, Camillo Ribi: None declared, Andrea Doria: None declared, Yannick Allanore: None declared DOI: 10.1136/annrheumdis-2021-eular.3048

\section{POS0319 PERFORMANCE OF PATIENT REPORTED OUTCOMES (PROS) IN SCLERODERMA PATIENTS WITH REDUCED LUNG FUNCTION IN AN OBSERVATIONAL COHORT}

M. G. Lazzaroni ${ }^{1}$, G. Abignano ${ }^{2,3}$, M. Wilson ${ }^{2}$, V. Kakkar ${ }^{2}$, F. Del Galdo ${ }^{2} .{ }^{1} A S S T$ Spedali Civili of Brescia, University of Brescia, Rheumatology and Clinical Immunology, Brescia, Italy; ${ }^{2}$ University of Leeds, Institute of Rheumatic and Musculoskeletal Medicine and NIHR Biomedical Research Centre, Leeds, United Kingdom; ${ }^{3}$ Azienda Ospedaliera San Carlo, Rheumatology, Potenza, Italy

Background: Patient Reported Outcomes (PROs) are used to capture disease impact on patients' Health Related Quality of Life (HRQoL) and they have been increasingly used as endpoints in clinical trials for Systemic Sclerosis (SSc). The DeSScipher project within the EUSTAR group highlighted dyspnea as one of the factors more strongly related with the highest SHAQ scores (1). Nevertheless, the SENSCIS trial in SSc-ILD (2) showed the efficacy of Nintedanib in reducing the annual rate of FVC loss, as compared to placebo, without significant changes in the PROs used as secondary endpoints (St. George's Respiratory Questionnaire and the FACIT-Dyspnoea questionnaire). Since patient's perspective is a crucial determinant to define the overall relevance of an intervention, the performance of PROs in reflecting different lung functional stages is a relevant issue in SSc. Objectives: To analyse in a prospective SSc cohort the inference of reduced lung function as measured by FVC on median PRO scores and the correlation among distinct commonly used PROs.

Methods: A cross-sectional study was performed on data exported from the STRIKE database regarding SSc patients followed in Leeds Scleroderma Programme for SSc. Data included records of periodical visits with scores of different PROs commonly used in SSc (Scleroderma-Health Assessment Questionnaire (SHAQ), Cochin Hand Function Scale (CHFS) and Borg dyspnoea scale) and FVC\%-predicted (\%pFVC) and DLCO\%-predicted (\%pDLCO). SHAQ score was calculated as the mean value of $\mathrm{HAQ}(0-3)$ with the average of the 7-VAS scores divided by 3.33. The 7-VAS (score 1-10) were 1: pain, 2: general function, 3: arthritis, 4: gastro-intestinal, 5: dyspnoea, 6: Raynaud Phenomena; 7: digital ulcers. The correlation of FVC with distinct PROs, and the inter-PRO correlation, were analysed through the non-parametric Spearman test.

Results: Complete data were available from 182 visits of 87 SSc patients (41 with diffuse and 46 with limited cutaneous involvement). Mean \%pFVC was 95.16 \pm 24.93 (median 95) and mean \%pDLCO was 59.31 \pm 16.51 (median 59). Overall, FVC and DLCO showed a moderate correlation with SHAQ $(r=-0.36, p<0.001$ and $r=-0.24, p: 0.001$ respectively), while Borg score showed a stronger negative correlation with FVC and DLCO ( $\mathrm{r}:-0.42$ and $\mathrm{r}-0.38, \mathrm{p}<0.001$ for both). In a sub-analysis of patients grouped by FVC, patients with FVC $50-70 \%$ showed a significant correlation of FVC with SHAQ ( $r=-0.47, p: 0.012)$, which was not present in patients with FVC 70-90\% (r:-0.23, p:0.13). VAS-5 dyspnoea and Borg were not associated with FVC in these two subgroups of patients.

Inter PROs analysis showed that CHFS score had a stronger correlation with $\mathrm{SHAQ}$ than Borg dyspnoea score in the overall population ( $r: 0.86 \mathrm{vs}$. $r: 0.57$, both $\mathrm{p}<0.001)$.

Conclusion: The analysis of a single centre prospective cohort of SSc patients, suggests a small inference of lung function in the overall SHAQ. The stronger correlation of SHAQ with CHFS, than with Borg score, suggests a higher weight of hand function on SHAQ in this population with relatively conserved lung function. In patients with $\% p F V C<70 \%$, the correlation with SHAQ was stronger than in patients with \%pFVC $>70 \%$, suggesting that mild reductions in FVC might not be perceived by the patients, or at least they might not modify HrQoL as measured by SHAQ.

REFERENCES:

[1] Jaeger VK, et al. Rheumatology 2017;57(3):441-50
[2] Distler O, et al. N Engl J Med 2019; 380:2518-2528.

Disclosure of Interests: Maria Grazia Lazzaroni Grant/research support from: Boehringer-Ingelheim, Giuseppina Abignano: None declared, Michelle Wilson: None declared, Vishal Kakkar: None declared, Francesco Del Galdo Consultant of: Astra-Zeneca, Boehringer-Ingelheim, Mitsubishi-Tanabe, Capella Biosciences, Kymab, Actelion, Grant/research support from: Astra-Zeneca, Boehringer-Ingelheim, Mitsubishi-Tanabe, Capella Biosciences, Kymab, Actelion DOI: 10.1136/annrheumdis-2021-eular.3505

\section{POS0320 POOR PROGNOSIS PREDICTION IN ANTI-MDA5 POSITIVE DERMATOMYOSITIS ASSOCIATED WITH INTERSTITIAL LUNG DISEASE: THE CROSS-CAR DECISION TREE MODEL}

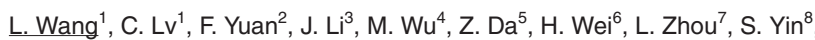
J. Wu ${ }^{9}$, W. Tan ${ }^{1} .{ }^{1}$ The First Affiliated Hospital of Nanjing Medical University, Department of Rheumatology, Nanjing, China; ${ }^{2}$ The Affiliated Wuxi People's Hospital of Nanjing Medical University, Department of Rheumatology, Wuxi, China; ${ }^{3}$ Huai'an First People's Hospital, Department of Rheumatology, Huai'an, China; ${ }^{4}$ The Third Affiliated Hospital of Soochow University, Department of Rheumatology, Changzhou, China; ${ }^{5}$ Affiliated Hospital of Nantong University, Department of Rheumatology, Nantong, China; ${ }^{6}$ Northern Jiangsu People's Hospital, Department of Rheumatology, Yangzhou, China; ${ }^{7}$ Changzhou Second People's Hospital Affiliated to Nanjing Medical University, Department of Rheumatology, Changzhou, China; ${ }^{8}$ Affiliated Hospital of Xuzhou Medical University, Department of Rheumatology, Xuzhou, China; ${ }^{9}$ The First Affiliated Hospital of Soochow University, Department of Rheumatology, Suzhou, China

Background: The prognosis of anti-melanoma differentiation-associated gene 5 positive dermatomyositis (anti-MDA5+ DM) - associated interstitial lung disease (ILD) is poor and heterogeneity.

Objectives: The aim of this study was to evaluate prognostic factors and to develop a simple and generally applicable bedside decision tree model for predicting outcomes in patients with anti-MDA5+ DM and to guide treatment.

Methods: We analyzed data for 246 anti-MDA5+ DM patients from Myositis Study Group-Jiangsu, a multicenter cohort across eighteen tertiary hospitals in Jiangsu province, from March 2019 to October 2020. The primary end point was all-cause death, and the secondary end point was occurring of rapidly progressive-ILD (rp-ILD). We used a multivariable Cox proportional hazards model to identify the independent prognostic risk factors of death and rp-ILD respectively. A decision-tree prediction model was developed by using data from 10 hospital of southern region $(n=163)$, with validation by using contemporaneous data from northern region $(n=83)$.

Results: To assess the risk of rp-ILD, we developed a combined risk score, the CROSS score, that included the following values and scores: C-reactive protein $(\leq 8 \mathrm{mg} / \mathrm{L}, 0 ;>8 \mathrm{mg} / \mathrm{L}, 3)$, anti-Ro52 antibody (negative, 0; positive, 4), Sex (Female, 0; Male, 2) and Short course of disease (More than 3 months, 0; Less than 3 months, 2). The mortality risk was identified by the CAR score, including C-reactive protein $(\leq 8 \mathrm{mg} / \mathrm{L}, 0 ;>8 \mathrm{mg} / \mathrm{L}, 1)$, Alanine Transaminase ( $\leq 50 \mathrm{units} / \mathrm{L}, 0$; $>50$ units/L, 1) and rp-ILD (non-rpILD, 0; rp-ILD, 3). We divided patients into three risk groups according to the CROSS score: low, 0 to 3; medium, 4 to 7; and high 8-11. And then Use of a simple decision tree prediction model permitted stratification into three different outcome prediction groups. High-risk patients had significantly higher mortality rates than low- and medium-risk patients in both discovery and validation cohorts $(p<0.0001)$.

Conclusion: The CROSS-CAR decision tree model is easy to evaluate the poor prognostic risk in MDA5+ DM patients during any follow-up period. Unnecessary lung examination, such as chest CT scan and arterial blood gas analysis was avoided in low- and medium- rpILD risk patients. The special ambulance, with red cross sign tagged on car in China, may help to screen the high risk patients and to guide further treatment.

Disclosure of Interests: None declared

DOI: 10.1136/annrheumdis-2021-eular.3514

\section{POS0321 \\ USE OF HYDROXYCHLOROQUINE AND SYSTEMIC SCLEROSIS: RESULTS FROM A PROSPECTIVE OBSERVATIONAL STUDY ON THE EUSTAR COHORT}

S. Bellando Randone ${ }^{1}$, H. Wilhalme ${ }^{2}$, C. Bruni ${ }^{1}$, E. Siegert ${ }^{3}$, P. Airo ${ }^{4}$, R. Irace ${ }^{5}$ O. Distler ${ }^{6}$, A. Doria ${ }^{7}$, L. P. Ananieva ${ }^{8}$, L. Czirják ${ }^{9}$, C. Denton ${ }^{10}$, Y. Allanore ${ }^{11}$, V. Riccieri ${ }^{12}$, A. Vacca $^{13}$, I. Foeldvari ${ }^{14}$, A. M. Hoffmann-Vold ${ }^{15}$, A. Gabrielli $i^{16}$, M. Matucci-Cerinic ${ }^{1}$, D. Furst ${ }^{1,2}$ on behalf of EUSTAR. ${ }^{1}$ AOU Careggi University of Florence, Division of Rheumatology, Florence, Italy; ${ }^{2}$ University of California at Los Angeles, Department of Medicine, Division of Rheumatology, Los Angeles, United States of America; ${ }^{3}$ Charité University Hospital, Rheumatology, Berlin, Germany; ${ }^{4}$ Spedali Civili di Brescia, Servizio di Reumatologia Allergologia e Immunologia Clinica, Brescia, Italy; ${ }^{5}$ II University of Naples, 